\title{
Fahr's Disease: A Case Report
}

\author{
Sinha $\mathbf{R}^{1}$, Sodhi $\mathrm{K}^{2}$, John $\mathrm{BM}^{3}$, Singh $\mathrm{D}^{4}$
}

${ }^{1}$ Dr. Rahul Sinha, MBBS, MD Resident (Paediatrics), ${ }^{2}$ Dr. Kirandeep Sodhi, MBBS, MD, Professor in Paediatrics, ${ }^{3}$ Dr. BM John, MBBS, MD (Paediatrics), Dr. Daljit Singh, MBBS, MD (Paediatrics), DM (Neonatology). All from the Command Hospital Air Force, Bangalore, Karnataka, India.

Address for Correspondence: Dr. Rahul Sinha, E-mail: drrahul_2000@yahoo.com

\begin{abstract}
We report a case of Fahrs disease in a 15year old girl presented to us with focal seizure with secondary generalisation. Clinically there were no abnormal findings. The CT scan (brain) showed multiple symmetric and extensive calcifications in the basal ganglia, thalamus, and dentate nucleus, subcortical white matter of cerebral and cerebellar areas. Presently the child is under followup with good seizure control with carbamezpine. This rare case of idiopathic Fahr's disease in a child, which has never been reported in Indian literature has been brought out to highlight this unusual condition and its differentiation from the commoner Fahr's syndrome.
\end{abstract}

Key words: Basal ganglia, calcification, Fahrs disease.

\section{Introduction}

E ahr's Disease is a rare degenerative neurological disorder characterized by the presence of abnormal calcium deposits and associated cell loss in certain areas of the brain (e.g. basal ganglia). The condition is often referred to as idiopathic basal ganglia calcification because there is no apparent explanation for such calcification ${ }^{1}$. We report a rare case of Fahr's Disease in a 15 year old female child.

\section{Case report}

A 15 year old female child who was a known case of seizure disorder on epileptic drugs since the age of 2 years presented to us with right sided partial motor seizure with secondary generalization. There was no family history of any similar disorder or any other neurological disorder. On clinical examination the weight and height were below $5^{\text {th }}$ centile. There was no other significant finding on general examination. Systemic examination including the neurological examination was normal. The developmental milestones were normal for age. The IQ test revealed score of 90 . The investigations revealed normal haematological parameters. The serum biochemistry revealed serum calcium $4.2 \mathrm{mg} / \mathrm{dl}$ (ionised) and the total calcium of $9.6 \mathrm{mg} / \mathrm{dl}$, serum phosphorus of $4.5 \mathrm{mg} / \mathrm{dl}$ and the serum Parathormone level $30 \mathrm{pg} / \mathrm{dl}$ (normal range; 9-65pg/dl). Thyroid function test was normal. The serum anti nuclear antibody, workup for intrauterine infections and ELISA - HIV were negative. Mantoux test (1TU PPD-RT23 with tween 80) was negative. The urine for metachromatic granules and aminoacidurias were negative. The arterial blood gas analysis was normal. Chest $\mathrm{x}$ ray and ultrasound abdomen did not reveal any abnormality. EEG showed features suggestive of generalised epilepsy. CT scan (brain) (Fig.1) revealed symmetric and extensive calcification in the basal ganglia, thalamus, dentate nucleus, subcortical white matter of cerebral and cerebellar areas. The child's seizures were controlled with carbamazepine and she was put on a regular outpatient follow up. 


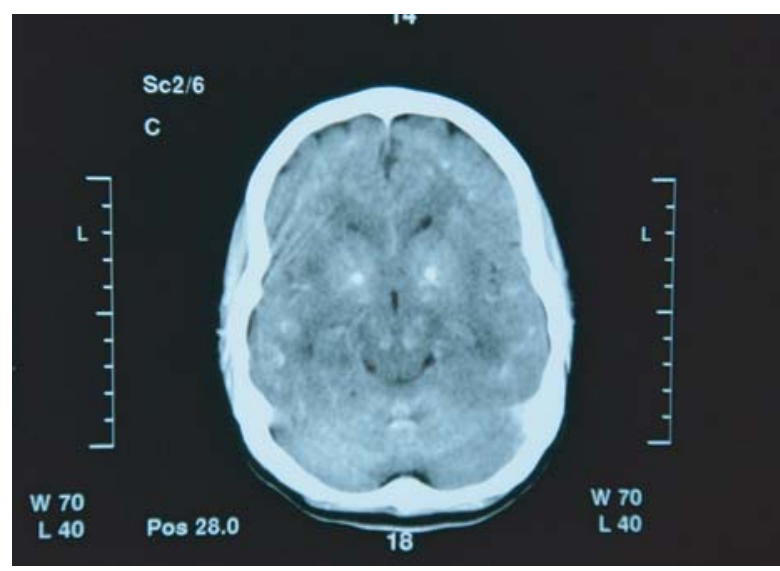

Fig. 1: Showing the CT scan image showing multiple symmetric calcification in basal ganglia, thalamus, dentate nuclei, subcortical white matter and cerebellum.

\section{Discussion}

Fahr's disease was first noted by German neurologist Karl Theodor Fahr in 1930. It is often familial and this form may be transmitted as an autosomal recessive trait or may have autosomal dominant inheritance. In other instances, the condition appears to be sporadic. Some experts suggest that the condition may sometimes result from an intrauterine infection ${ }^{2}$.

Patients with Fahr's disease often present with movement disorders, such as parkinsonism, paresis, dystonia and speech impairment. They may also have other manifestations including stroke-like events, often combined with psychiatric conditions, such as psychosis, mood disorders, and dementia. Although children with Fahr's disease are usually seen with motor deficits, about $40 \%$ of the patients with Fahr's disease are seen with primarily cognitive and other psychiatric findings ${ }^{3}$. The index child however did not have any neurological abnormalities or psychiatric manifestations.

Fahr's disease, however, needs to be distinguished from Fahr's syndrome in which basal ganglia calcification is secondary to some other disorder, such as hypoparathyroidism ${ }^{4,5}$. Basal ganglia calcification may also be seen in various other conditions like CMV infection, neurocysticercosis, toxoplasmosis, neurobrucellosis, tuberculosis, HIV infection, astrocytomas, calcified infarct, pseudohypoparathyroidism, hyperparathyroidism, lead intoxication, hypervitaminosis D, radiotherapy, mitochondrial encephalopathies, leukodystrophic diseases, lupus and tuberous sclerosis. Fahr's disease should also be distinguished from incidentally found basal ganglia calcification in elderly population. Some studies have shown presence of elements (zinc, aluminium, copper) along with cerebral calcifications.

CT scan is considered to be the best modality of investigation in the diagnosis of Fahr's disease where unenhanced CT reveals dense calcifications within the basal ganglia, subcortical white matter of the posterior parietal lobes, and the dentate nuclei of the cerebellum.

However on magnetic resonance imaging (MRI), the signal may be variable. On T1 weighted images, low signal is due to the low proton density of calcium and other mineral ions present in higher concentration. However they might present hyperintense signal, due to proteins and mucopolysaccharides binding the mineral ions. The calcification might also be undetected on MRI when they are in an intermediary stage ${ }^{6}$.

There is neither specific cure for Fahr's disease, nor a standard treatment. Case reports have suggested that haloperidol or lithium carbonate may help in patients with psychotic symptoms ${ }^{7}$.

In our case, the child presented with seizures. All the common causes of Fahr's syndrome were excluded and CT scan showed classical symmetrical basal ganglia involvement. This rare case of idiopathic Fahr's disease in a child, which has never been reported in Indian literature, has been brought out to highlight this unusual condition and its differentiation from the commoner Fahr's syndrome.

\section{References}

1. T. Fahr: Idiopathische Verkalkung der Hirngefässe. Zentralblatt für allgemeine Pathologie und pathologische Anatomie 1931; 50: 129-33.

2. Perez MA, Martin PE, Sarmiento GE, et al. Fahr's disease and Hypocalcemic Syndromes: Presentation of a Clinical Case. An Med Interna 1992; 9:495-7.

3. Benke T, Karner E, Seppi K, Delazer M, Marksteiner J, Donnemiller E. Subacute Dementia and Imaging Correlates in a Case of Fahr's Disease. J Neurol Neurosurg Psychiatry 2004; 75:1163-5.

4. Guerreiro MM, Scotoni AE. Calcificações dos gânglios da base na infância. Arq Neuropsiquiatr 1992;50:513-8.

5. Oliveira JR, Spiteri E, Sobrido MJ, et al. Genetic Heterogeneity in Familial Idiopathic Basal Ganglia Calcification (Fahr disease). Neurology 2004; 63:2165-7.

6. Scotti G, Sciafla G, Tampieri D, Landoni L. MR Imaging in Fahr disease. J Comput Assist Tomogr 1985; 9:790-2

7. Munir KM. The Treatment of Psychotic Symptoms in Fahr's disease with Lithium Carbonate. J Clin Psychopharmacol 1986; 6(1):36-8. 